\title{
A RELAÇÃO DOS ESTUDANTES COM OS PROFESSORES NO ENSINO MÉDIO: NARRATIVA E EXPERIÊNCIA
}

- LUCAS DA SILVA MARTINEZ

Universidade Federal de Santa Maria

SUELI SALVA

Universidade Federal de Santa Maria

Este artigo é produto de uma dissertação de mestrado que versa sobre as relações com a escola, o aprender e os conhecimentos escolares de jovens estudantes no Ensino Médio. Objetiva discutir as relações que tais jovens estabelecem com seus professores e suas práticas, no Ensino Médio, e o impacto dessas em sua interação com a escola. A metodologia adotada é de natureza qualitativa e biográfico-narrativa, em entrevistas narrativas com seis estudantes de licenciatura de uma universidade na região sul do país, analisadas a partir da análise textual discursiva. Com base na análise realizada, enfocando o diálogo entre os jovens estudantes e professores, percebe-se que a experiência dos jovens é marcada, respectivamente, de forma positiva e negativa, através de, por um lado, relações de amizade, de aprendizagem e de dialogicidade, e, por outro lado, pelo autoritarismo, a licenciosidade e a distância estabelecida. Entendese que, pelo fato dos jovens viverem a escola por meio de sua sociabilidade, estudar as relações dos jovens com os professores pode se configurar em uma estratégia metodológica importante para a pesquisa em educação. Cabe ainda destacar a importância das pesquisas narrativas e em educação considerarem a experiência dos jovens estudantes, ampliando o olhar sobre a escola.

Palavras-chave: Ensino Médio. Jovens estudantes. Professores. Práticas.

\section{ABSTRACT THE RELATIONSHIP OF STUDENTS WITH TEACHERS IN HIGH SCHOOL: NARRATIVE AND EXPERIENCE}

This article is the product of a master's thesis that deals with the relations with the school, the learning and the scholastic knowledge of young students in High School. It aims to discuss the relation- 
ships that the such young people establish with their teachers and their practices in High School and their impact on their interaction with the school. The methodology adopted is of a qualitative and biographical-narrative nature, in narrative interviews with six undergraduate students from a university in the southern region of the country, analyzed from discursive textual analysis. On the basis of the analysis carried out, focusing on the dialogue between young students and teachers, it is noticed that the experience of young people is marked, respectively, in a positive and negative way, through, on the one hand, relations of friendship, learning and dialogue, and, on the one hand, by authoritarianism, licentiousness and established distance. It is understood that, because the young people live the school through their sociability, studying the relations of the young with the teachers can be configured in an important methodological strategy for the research in education. It is also important to emphasize the importance of narrative research and in education consider the experience of young students, broadening the look on the school. Keywords: High School. Young students. Teachers. Practices.

\section{RESUMEN LA RELACIÓN DE LOS ESTUDIANTES CON LOS PROFESORES EN LA ENSEÑANZA MEDIA: NARRATIVA Y EXPERIENCIA}

Este artículo es producto de una disertación de maestría que versa sobre las relaciones con la escuela, el aprendizaje y los conocimientos escolares de jóvenes estudiantes en la Enseñanza Media. Objetiva discutir las relaciones que tales jóvenes establecen con sus profesores y sus prácticas en la Enseñanza Media y el impacto de éstas en su interacción con la escuela. La metodología adoptada es de naturaleza cualitativa y biográfica-narrativa, en entrevistas narrativas con seis estudiantes de licenciaturas de una universidad en la región sur del país, analizadas a partir del análisis textual discursivo. Con base en el análisis realizado, enfocando el diálogo entre los jóvenes estudiantes y profesores, se percibe que la experiencia de los jóvenes está marcada, respectivamente, de forma positiva y negativa, a través de, por un lado, relaciones de amistad, de aprendizaje y de diálogo, y, por un lado, el otro lado, a través del autoritarismo, de la licenciosidad y de la distancia establecida. Se entiende que, por el hecho de que los jóvenes viven la escuela a través de su sociabilidad, estudiar las relaciones de los jóvenes con los profesores puede configurarse en una estrategia metodológica importante para la investigación en educación. Cabe destacar la importancia de las investigaciones narrativas y en educación considerar la experiencia 
de los jóvenes estudiantes, ampliando la mirada sobre la escuela.

Palabras clave: Enseñanza Media. Jóvenes estudiantes. Profesores. Prácticas.

\section{Primeiras palavras}

Este artigo é fruto da dissertação de mestrado intitulada "Eu não gostava nem odiava porque eu não entendia nada!": relações com a escola, o aprender e os conhecimentos escolares no Ensino Médio' (MARTINEZ, 2018), que teve por interesse produzir narrativas, baseadas nas memórias de jovens estudantes de licenciatura da Universidade Federal de Santa Maria (UFSM), sobre a escola de Ensino Médio, suas relações com o aprender, os conhecimentos escolares e os professores e colegas. A pesquisa está vinculada ao projeto "As crianças e jovens estudantes em contextos educativos: olhares sobre práticas educativas, culturas, relações de gênero e políticas públicas" e ao grupo de pesquisa intitulado Filosofia, Cultura e Educação (FILJEM/CNPq).

O Ensino Médio é um campo de constantes confrontos. A discussão atual, que engloba a reforma que instituiu o "Novo Ensino Médio", através da Lei 13.415 , de 2017, põe em risco o caráter "[...] público, inclusivo e universal" (SILVA; SCHEIBE, 2017, p. 19) da escola, pois prima pela formação para o trabalho e, dentro de uma lógica mercantil, reduz as possibilidades formativas oferecidas aos jovens. Silva e Scheibe (2017), Gonçalves (2017) e Ferreti e Silva (2017), em seus respectivos artigos, analisam o movimento político subjacente a essa reforma. Podemos apontar que, dentre tais aspectos políticos, destacam-se a formação do jovem atrelada ao mercado de trabalho, o que inviabiliza estudos gerais para a universidade; a jornada em tempo integral, que exclui as

1 O presente trabalho foi realizado com apoio da Coordenação de Aperfeiçoamento de Pessoal de Nível Superior - Brasil (CAPES) Código de Financiamento 001. possibilidades de estudo para os jovens que trabalham; a redução do currículo, que dá ênfase em avaliações de larga escala (nacionais, internacional e de ingresso, como é o caso do Exame Nacional do Ensino Médio - ENEM), que são usadas como parâmetro para a formação de "qualidade", entre outros (MARTINEZ; SALVA, 2018).

Este é o cenário educacional e político em que esta pesquisa se inseriu. Embora ela tenha se iniciado antes da aprovação da Lei do "Novo Ensino Médio", esta problematização a acompanha, principalmente, quando questionamos o conhecimento escolar, o papel da escola e a formação dos jovens, entre outros aspectos.

Estas reformas protagonizadas por diferentes empresários, divulgadas pelas mídias e vivida por estudantes e professores, nos fazem pensar que, em meio a tantas críticas, nada bom é produzido na escola. Entretanto, será que ela deve acabar, ou ser partida, recortada, esfacelada como propõe esta reforma? o que a escola produz?

Junto ao referencial de Masschelein e Simons (2017), na obra Em defesa da escola: uma questão pública, defendemos um outro olhar sobre a escola: uma escola que, a partir da reflexão e do tempo livre (sem necessidade produtiva no sentido capitalista do termo), o mundo é explorado, posto em evidência. A formação para o mercado ou a construção de competências não é tão importante quanto a relação do estudante com o conhecimento escolar, o que permite que, obtendo esse conhecimento do mundo, use-o de diferentes maneiras. Assim, estamos preocupados com outras possibilidades: qual a qualidade do 
conhecimento escolar oferecido aos jovens? Quais as relações que eles estabelecem com esses conhecimentos? Quais as relações que eles estabelecem com professores e colegas estudantes? Qual o sentido do conhecimento escolar em suas vidas? A lógica é outra, e se opõe a visões tradicionais da escola.

Em outro trabalho (MARTINEZ; SALVA, 2017) exploramos aspectos referentes à relação dos jovens com as metodologias de aula dos professores, suas aprendizagens, inclusive na própria dissertação já mencionada (MARTINEZ, 2018). Nesse trabalho, entretanto, damos ênfase às relações construídas pelos jovens com os seus professores e as práticas docentes, que influenciam o seu estar na escola, o seu aprender e que são marcadas de formas positivas e negativas. Por isso, considerando as narrativas sobre o Ensino Médio de jovens estudantes de licenciatura, o objetivo do trabalho é discutir as relações que os jovens estudantes estabelecem com seus professores e suas práticas, no Ensino Médio, e o impacto dessas em sua interação com a escola.

O uso do termo relação vem da teoria da relação com o saber de Bernard Charlot (2000; 2013). Estar na escola não significa fazer o uso deliberado/controlado da racionalidade em uma atividade de estudo, simplesmente. É se relacionar, ser afetado pelas disciplinas, conhecimentos, atividades, professores e colegas, e experienciar, no sentido proposto por Larrosa (2002), ser atravessado por essas experiências.

Assim, Charlot (2013) nos adverte que, para aprender, é necessário o estabelecimento de uma atividade intelectual (atividade, coerente com motivo e objetivo), se mobilizar em direção ao conhecimento (mobilizar recursos, estratégias e pensamentos, em direção à compreensão) através do sentido que o sujeito estabelece com determinado conhecimento. Isso se soma ao prazer de aprender, de saber, de conhecer mais. Assim, ao nos perguntarmos: por que o jovem continua na escola? O que ele aprende e gosta de aprender na escola? De quais professores e disciplinas ele gosta e por quê? Quais seus projetos de futuro? Quais os motivos que o mobilizam em direção aos estudos ou a outras direções (trabalho, ingresso na educação superior, "prêmios" dados pelos pais etc.)? Estas e outras perguntas, na mesma direção, estão tratando diretamente da relação do jovem com a escola, o seu aprender e os conhecimentos escolares.

Como entender essas relações? Professores observam seus estudantes no cotidiano da escola e compreendem como eles se manifestam perante as relações, atividades, disciplinas. Mas essa observação é restrita. Cabe, então, desenvolver uma escuta, como nos adverte Alberto Melucci, em trecho na apresentação da sua obra $O$ jogo do eu: a mudança de si em uma sociedade global (FOLLMANN; FISCHER, 2004). Essa escuta é o fundamento para uma forma de ensinar e pesquisar os/com jovens, é um recurso sociológico que permite ao outro dizer aquilo que ele pensa. Assim, nessa pesquisa, lançamos mão das narrativas, a partir de entrevistas, com jovens estudantes de licenciatura, nas quais esses jovens refletem sobre suas experiências no Ensino Médio.

Por fim, destacamos a contribuição de Freire $(1983 ; 2016)$ em relação ao diálogo necessário à prática educativa, bem como o papel do professor e as relações que pode estabelecer com os estudantes. Nesse sentido, a teorização de Freire permite vislumbrar um horizonte dialógico para a prática educativa, no qual professores e estudantes se reúnem em torno dos conhecimentos escolares (e da vida) e o criticam, o reelaboram (FREIRE; SHOR, 2006). Desse modo, a educação (formal ou não) permite a prática da liberdade, em oposição ao autoritarismo, possibilitando a denúncia do mundo desigual em que vivemos. 
Este artigo se divide em quatro partes: a introdução, que lança luz sobre o contexto da discussão proposta; a metodologia, que explora a forma como a pesquisa foi realizada; a discussão das narrativas elaboradas pelos jovens e, as considerações finais.

\section{Perspectiva metodológica}

Neste estudo foi adotada a perspectiva da pesquisa qualitativa biográfico-narrativa. Tal perspectiva foi escolhida a partir de duas ideias centrais: a de que a experiência de cada sujeito é importante e, portanto, requer um nivel de atenção ao individual (MELUCCI, 2005; LARROSA, 2002) e, que aos poucos a pesquisa em educação foi abrangendo o universo de significados produzidos pelos atores sociais, ou seja, professores, estudantes, comunidade escolar em geral (GHEDIN; FRANCO, 2011). Desse modo, adotar a perspectiva qualitativa de matriz narrativa é, portanto, um exercício de escuta da voz do outro, no caso desta pesquisa, a voz de jovens estudantes.

Conforme apontam Souza e Soares (2008, p. 192), a pesquisa biográfico-narrativa:

[...] assume a complexidade e a dificuldade de atribuir primazia ao sujeito ou à cultura no processo de construção de sentido. Ao longo de seu percurso pessoal, consciente de suas idiossincrasias, o indivíduo constrói sua identidade pessoal, mobilizando referentes que estão no coletivo. A abordagem biográfico-narrativa pode auxiliar na compreensão do singular/universal das histórias, memórias institucionais e formadora dos sujeitos em seus contextos, pois revelam práticas individuais que estão inscritas na densidade da história.

Assim, defender a narrativa como uma forma de pesquisar com jovens (MARTINEZ, 2017) é defender o estatuto da experiência pessoal como uma forma de compreensão do universo social, neste caso, escolar. As pesquisas macrossociais levantam dados importantes que permitem a estratificação, categorização, uma “imagem ampliada" da realidade, mas, através das entrevistas narrativas e da valorização da experiência, podemos nos aproximar da realidade microssocial e produzir elementos que permitam uma outra interpretação de dados macrossociais. "Essa compreensão da narrativa permite perceber a realidade como um processo dinâmico, criativo, em que tanto o narrador quanto a realidade renascem, tornando única cada narrativa" (QUEIROZ, 2017, p. 475). A necessidade de pesquisar narrativamente a experiência de jovens amplia-se quando as próprias pesquisas educacionais denunciam que os temas principais dos estudos narrativos tratam da identidade e da profissão docente (CAVACO, 2018). É preciso, portanto, ampliar os protagonistas das pesquisas, considerando não só os professores, mas os estudantes, nos diferentes níveis/etapas de ensino.

Para este estudo, foram realizadas entrevistas narrativas com seis jovens estudantes de licenciatura da UFSM. Tais entrevistas partiram de um roteiro de perguntas abertas, explorando aspectos relativos à escolarização, relações entre professores, estudantes e colegas, disciplinas com maior ou menor afinidade, elementos que compõe uma aula interessante, dentre outras questões. Neste artigo, limitamo-nos a analisar as narrativas que dizem respeito à relação dos estudantes com seus professores e com as práticas docentes que estes últimos desenvolvem.

Segundo Bolivar, Domingo e Fernández (2001), as entrevistas narrativas têm por interesse a escuta de histórias dos participantes, na tentativa de compreender não só aspectos individuais, senão também indícios de fenômenos que se mostram na realidade macrossocial. Além dos dados produzidos, a entrevista narrativa permite a autorreflexão dos pesquisadores e dos sujeitos participantes, considerando que estes, ao organizar os fatos e histórias em uma narrativa, os ressignificam, 
trazendo à tona eventos importantes que, de algum modo, os marcaram. Por isso, entendese que narrar lida com a identidade de quem narra, é como se ver no espelho (MELUCCI, 2001).

O primeiro passo foi escolher os estudantes para participar da pesquisa. Com base em conversas informais com outros estudantes de licenciatura, e o próprio processo de relembrar as experiências do Ensino Médio de um dos autores do artigo, percebemos que a trajetória era algo marcado de forma positiva e negativa, o que despertou nossa atenção sobre a escolarização dos jovens e como eles teriam chegado à Educação Superior, em licenciaturas. Decidimos, portanto, entender como foi a experiência desses jovens no Ensino Médio.

Parte desta escolha se deu pela possibilidade proposta por Tardif (2010), ao entender que os professores carregam longa carga de experiência proveniente da escola, e que, grande parte do seu repertório de ação na escola, foi vivido por eles. Assim, refletir sobre o passado escolar é, de certo modo, tentar entender porque "agimos como agimos" enquanto docentes. Esse viés de estudo não será explorado nesse artigo, mas é, entretanto, um campo proficuo para a análise das narrativas. Souza e Soares (2008, p. 197) levando em conta esse movimento de pensar as experiências vividas e a formação, escrevem que a pesquisa biográfica, ao permitir ao sujeito a sua autorreflexão, permite também “[...] compreender as influências sociais, econômicas, políticas, religiosas, culturais e educacionais presentes na própria existência [...] compreendendo assim as influências referentes às escolhas que são feitas no decorrer da vida".

Mesmo que a relação entre a escola e a docência não seja realizada, no âmbito desta pesquisa, ela é realizada no ato de narrar, por parte dos estudantes. Isso diz respeito ao caráter da narrativa indicado por Clandinin e Connelly
(2015): ela é introspectiva, pois lida com a dimensão dos sentimentos, desejos, esperanças; mas é também extrospectiva, pois se relaciona ao meio no qual os narradores estão inseridos; retrospectiva e prospectiva, pois lida com a temporalidade no sentido de que, ao narrar, quem narra se relaciona com seu passado, com a memória, e com seu futuro, na esperança do acontecimento de determinados fatos.

De acordo com o Portal de indicadores da UFSM a instituição possui 23 licenciaturas (MARTINEZ, 2018). Por meio de sorteio, foram selecionadas as seguintes licenciaturas: Química, Teatro, Ciências Sociais, Educação Física, Física e Matemática. Foi feito um contato presencialmente e por e-mail com a secretaria de cada curso. De um universo de 805 estudantes, não obtivemos nenhum retorno. Passamos, então, a buscar outra alternativa.

Enviamos uma mensagem à uma página ${ }^{2} \mathrm{e}$ à um grupo do Facebook ${ }^{3}$ vinculado à universidade. Postamos a seguinte mensagem: "Procuro jovens do sexo masculino e feminino dos cursos de licenciatura em Física, Educação Física, Matemática, Ciências Sociais, Teatro e Química para entrevista sobre vivências no Ensino Médio. Quem estiver interessado é só curtir a postagem que eu entro em contato. Valeu!". Em pouco tempo, os estudantes começaram a nos contatar pelo Facebook, porém estudantes do curso de Matemática não conseguiram comparecer à entrevista. Logo, optamos por substituir o curso de Matemática pela Pedagogia, diante do interesse de uma estudante em participar. Assim, foram entrevistados os seguintes sujeitos: Ilia (Ciências Sociais), Jean (Física), Christine (Educação Física), Aline (Pedagogia), Leonardo (Teatro) e Diana (Química). Todos os nomes adotados são fictícios, protegidos pelo

2 SPOTTED UFSM. Facebook. Disponivel em: <https: / / www.facebook.com / Spotted-UFSM-930267327004173/>. Acesso em: 20 out. 2017.

3 UNIVERSO CEU II. Facebook. Disponível em: <https:// www.facebook.com/groups/universoceu2/?ref=br. rs>. Acesso em: 20 out. 2017. 
compromisso firmado no Termo de Consentimento Livre e Esclarecido (TCLE) assinado pelos estudantes.

Assim que realizadas e transcritas, as entrevistas foram analisadas à luz das orientações de Moraes (2003), em relação à metodologia da análise textual discursiva. A partir da desmontagem dos textos, sua categorização e reorganização, foram constituídas várias categorias. Neste artigo, exploramos algumas categorias, conforme o recorte já proposto ao longo do texto.

\section{Da relação com o saber: uma discussão ampla}

Como já apontado anteriormente, o conceito que gerou esta pesquisa é o de relação com o saber, de Bernard Charlot (2000; 2013).

Em diferentes textos, Charlot busca explicitar essa relação. Tem por base a visão antropológica de que o ser humano está condenado à aprendizagem. Assim, se as relações com o saber são relações com o aprender, podem ser entendidas em todos os âmbitos da vida. Além disso, baseia-se na sociologia, principalmente quando reivindica uma sociologia que, ao contrário da sociologia da educação da década de 1970, não reduza os estudantes à condição familiar e social (crítica direta aos teóricos reprodutivistas), mas que se desenvolva uma "sociologia do sujeito" ou, como escreve Lahire (2002), uma "sociologia psicológica", com ênfase no individual, na história dos sujeitos, na sua ação, na posição que eles ocupam no mundo. Essas perspectivas permitem uma visão ampliada da relação com o saber, o que faz Charlot (2000, p. 79) declarar que:

Que faz o pesquisador que estuda a relação com o saber? Estuda relações com lugares, pessoas, objetos, conteúdos de pensamento, situações, normas relacionais, etc.; na medida em que, é claro, está em jogo a questão do aprender e do saber. Analisa, então, por exemplo, relações com a escola, com os professores, com os pais, com os amigos, com a matemática, com as máquinas, com o desemprego, com o futuro, etc.

Para pensar essa relação (estar em relação, relacionar-se, vincular-se, desejar, mobilizarse em direção à algo, identificar-se) ele indica alguns elementos, que podemos destacar: a mobilização (mobilização interna, depende das características intrínsecas do sujeito, do desejo, ou da falta de desejo), o prazer (dimensão da fruição do desejo), o sentido (articulado ao que já é sabido, conhecido, o encontro do desejo com aquilo que o sana) e a atividade intelectual (atividade, encontro do motivo e objetivo). Portanto:

Aprender requer uma atividade intelectual. Só se engaja em uma atividade quem the confere um sentido. Quando esse sentido é afastado do resultado visado pela ação de estudar, o engajamento nesta é frágil. Ao contrário, quando motivo e objetivo coincidem, esta faz muito sentido e sente-se prazer ao desenvolvê-la e, ainda mais, ao atingir o objetivo. Atividade, sentido e prazer: esses são os termos da equação pedagógica a ser resolvida. (CHARLOT, 2013, p. 146)

Neste artigo, levantamos relações específicas: com os professores e suas práticas. Em outras palavras: os jovens aprendem na escola, com quais professores? 0 que esses professores fazem? Quais práticas desenvolvem? Que tipo de relação (afetiva) desenvolvem com os estudantes? Na próxima seção, exploramos algumas narrativas produzidas pelos estudantes.

\section{"Tanto que esse professor de filosofia é meu amigo, sabe?": a amizade como elemento de relação com o saber}

Um dos aspectos destacados nas narrativas dos jovens estudantes é a relação próxima 
com os professores, o que, para muitos, se traduz em amizade. A amizade, como um tema tratado filosoficamente e, por muito tempo, ignorado no campo social, ganha destaque, ao falarmos sobre a juventude. Para Salva (2008), muitas pesquisas com jovens tratam da amizade na juventude, porém sobre outra ótica, como relações de socialização, entre outras.

A amizade enquanto sentimento indica proximidade, afeição, reconhecimento, acolhimento, compromisso. Salva (2008), ao citar Aristóteles, entende que o mesmo compreendia a amizade a partir de três aspectos: pela utilidade, pelo prazer e pelo bem. As narrativas dos jovens estudantes não deixam claro por quais desses aspectos os mesmos estabelecem uma relação de amizade com os professores, mas esclarecem, entretanto, que de algum modo, um professor ou outro acaba se tornando um amigo, talvez pelo tempo de convívio e pelos diálogos, pela cumplicidade. Para Leonardo e Christine:

Tanto que esse professor de filosofia é meu amigo, sabe? (LEONARDO)

[...] ela fazia a gente entender os conteúdos e também era minha amiga. (CHRISTINE)

Para Diana, a amizade é marcada tanto pela presença, quanto pela saudade, pelo tempo vivido, ressignificado pela memória:

[...] a minha experiência sempre foi boa, assim, sempre tive bons professores, próximos, muito próximos, muito amigos também, sempre fui muito amiga de professores, tanto que uma das escolhas de fazer química foi muito influência de professores, os melhores professores que eu tive foram de química. Coloquei isso na minha apresentação de estágio, e eram mais compreensivos. Assim, tive uma boa experiência [...] cansei de chorar por despedida de professor, meu Deus... cada troca de professor... era assim... nós chorava sabe? "Ah, vou perder aquela professora". E o melhor de tudo isso é que até hoje eles lembram da gente, como a gente lembra deles, né, no face $e^{4}$ por exemplo, a gente acompanha, eles acompanham, e nesses momentos, assim, têm orgulho... dá força... acho que para o professor também né? É legal ver até onde o aluno que passou por ti vai, né? Acho que também é bem feliz da parte deles, né? (DIANA)

Essa relação de amizade aparece como expectativa, orgulho, compromisso, compreensão, retribuição. Parece que a relação entre professor e estudante, quando se torna amizade, rompe com um distanciamento e cria uma proximidade que, às vezes, é necessária na prática docente. Freire (2016) destaca, no entanto, que na relação é preciso certo tipo de equilíbrio para que a balança não pese somente para um lado: seja o da afetividade exacerbada, que compromete a postura do professor e a sua autoridade, ou da severidade, da frieza e distância. Isso se torna importante para pensar que na prática não é necessária uma falsa separação entre "[...] seriedade docente e afetividade" (FREIRE, 2016, p. 138).

Quando Diana indica que há um afeto implicado, que há uma saudade, um sentimento de força, nas entrelinhas chama atenção para a reciprocidade, o reconhecimento, um querer bem entre professor e estudante. Para Melucci (2004), é o reconhecimento do outro que nos ajuda a definir quem nós somos, como um espelho, no qual podemos entender o que somos e o que não somos. Por isso as relações de amizade estabelecidas, sejam com quem for, sempre fazem parte de um processo complexo e ambíguo de oposição e de identificação, de conselhos e dissensões e isso pode permitir que cada sujeito se perceba como sujeito individual e coletivo, autônomo e dependente.

Salva (2008, p. 307) declara que a amizade diz respeito ao acolhimento e ao bem querer daqueles que consideramos amigos, e que:

0 ato de acolher e ser acolhido torna a amizade desejável porque faz parte da felicidade de sa-

4 Abreviação popular de Facebook. 
ber que estamos protegidos por nossos amigos, mas não somos dependentes deles. É bom saber que eles existem, mesmo que nunca necessitemos efetivamente de sua ajuda; fortalece ter a confiança de que poderemos contar com os amigos, caso necessitemos deles.

No entanto, raramente desenvolvemos uma amizade significativa com todos à nossa volta e podemos dizer ao contrário: a amizade se dá em pequenos espaços, importando mais sua qualidade e o sentimento compartilhado do que a quantidade de amigos. A amizade implica aproximação e, portanto, nem sempre se dá facilmente porque depende de duas pessoas. Como já dito, a amizade implica o querer bem. Em relação a isso, Freire (2016, p. 138) declara que:

Esta abertura ao querer bem não significa, na verdade, que, porque professor, me obrigo a querer bem a todos os alunos de maneira igual. Significa, de fato, que a afetividade não me assusta, que não tenho medo de expressá-la. Significa esta abertura ao querer bem a maneira que tenho de autenticamente selar o meu compromisso com os educandos, numa prática específica do ser humano.

Com base em outros autores, Salva (2008, p. 319) aponta que, na juventude, a amizade é um importante recurso para a construção da identidade longe da família. As amizades formam-se em um espaço em que: "Os segredos, as confidências, as intimidades, os riscos e as novas experiências, normalmente divididas com os amigos, aliviam a tensão que produzem internamente, encorajando as jovens a tomar outras atitudes".

Mesmo falando de uma realidade específica de sua pesquisa (o grupo de amizade entre jovens mulheres), a argumentação da autora é válida para nós. Os jovens passam quatro horas por dia ou mais dentro da escola. Nesse espaço longe da família, também acontecem coisas que os marcam, e de algum modo eles constituem amigos para desabafar, trocar ideias. Isso não exclui a possibilidade de que isso também aconteça entre o professor e o estudante. Em um trecho narrativo de Leonardo, ele dá a entender que ainda divide ideias com seu professor, mesmo que o referido estudante já não se encontre mais na escola: "Uma questão que eu conversei com ele [o professor de filosofia] inclusive ontem [...]" (LEONARDO). Essa relação, várias vezes não construída, para não comprometer a autoridade entre professor e estudante, configura-se como um vínculo importante, inclusive de permanência no espaço escolar (ABRANTES, 2003), de inspiração ou de exemplo, lembrando a fala de Christine. Quase todos os jovens falam de algum professor específico, que os marcou (de forma positiva ou negativa), que se tornou exemplo para eles (ou não), e alguns poderiam até ser considerados como amigos. Nesta direção, Freire (2016, p. 64) declara que:

O professor autoritário, o professor licencioso, o professor competente, sério, o professor incompetente, irresponsável, o professor amoroso da vida e das gentes, o professor mal-amado, sempre com raiva do mundo e das pessoas, frio, burocrático, racionalista, nenhum desses passa pelos alunos sem deixar sua marca. Daí a importância do exemplo [...].

Dessa forma, consideramos que, muitas vezes, essa relação de amizade pode "afetar" ou constituir-se uma variável do processo de estar na escola e, pela empatia, aprender. De algum modo, quando se constitui uma relação de amizade, essa relação pode facilitar o diálogo e permitir que o jovem se aproxime do professor e, consequentemente, do discurso pedagógico da disciplina que ele ministra. $\mathrm{Na}$ entrevista com Leonardo, em vários momentos, ele se remete ao professor de Filosofia, com um sorriso no rosto, referindo-se àquele que é seu amigo, aquele the apresentou outra visão de mundo e que, ainda hoje, passado algum tempo, continua uma referência importante em sua vida. 
"Era uma prof. que conversava

\section{com a gente": o diálogo como} mote para a aprendizagem

Ao analisar as narrativas produzidas percebemos que grande parte delas destacava a relação com os professores, em especial, aqueles professores que em sua prática mantêm uma relação de diálogo com os estudantes.

Era na sala de aula mesmo, mas não era assim, quadro, era muito diálogo sabe? Principalmente a professora de fisica, assim, ela fazia umas piadas de fisica, fazia a gente dar risada e a gente acabava adorando a aula dela, que é um terror a fisica do Ensino Médio, porque é só conta e fórmula, então ela ia, contava uma história, falava, às vezes também né, da história de um fisico e ainda fazia piada, ela era muito engraçada, fazia a gente gostar. A de química era também muito desse tipo [...]. (DIANA)

Eu sei bastante coisa do corpo humano, e tal, $e$ isso ficou bem fixo na minha, não é nem fixo, não porque ficou fixo, é porque a gente vivenciava isso, era uma aula... tipo essas daqui da universidade, algumas aulas daqui, algumas aulas "decentes", que é não com o livro didático e não com o quadro, mas uma conversa, era uma prof. que conversava com a gente. Dai tinha muita gente que reclamava que "ah, que fulana não dá nada pra gente anotar, ela só conversa com a gente". Só que aquela conversa não era... ela não depositava, era uma troca, era um negócio... era bom. (ALINE, grifo nosso)

Estes jovens estudantes demonstram ter a mesma noção de professor: aquele que conversa, que troca ideias, que acha uma forma de captar a atenção dos estudantes através de uma postura mais próxima, dialógica, muitas vezes através do humor. Através dessa abertura, desse outro modo de se relacionar com os estudantes, é possivel construir outras atividades, por exemplo, as descritas por Christine:

Só essa.... com essa professora de português que ela fez a gente fazer um, tipo um júri assim que tinha um advogado, um réu e tal, e a gente fez tipo um teatro, assim [...]. (CHRISTINE)
Ilia chama a atenção para a possibilidade de trazer anseios, questões, interesses, e estes serem reconhecidos pelos professores como temas de interesse para os estudantes:

Mas o que tornavam as aulas diferentes ou mais interessantes eu acho que era de como o professor trabalharia com a gente ou às vezes eles falavam: "tragam alguns questionamentos sobre tal tema pra gente discutir em aula" ou "tragam diferentes assuntos que estejam ligadas à área de... o que está sendo discutido na sociedade agora e que venham ser possiveis temas de redação no ENEM" por exemplo. (ILIA, grifo nosso)

Ilia complementa:

Essa forma de ensino que nós temos de trabaIhar muito com o livro, ou questão de leitura, de trabalharmos sentados, do professor auxiliando... é bacana, só que com a nossa diferença de geração, de como nós interagimos uns com os outros de uma maneira mais dinâmica, de mais ação, não digo de mais energia mas hoje nós temos uma liberdade maior, de podermos falar em sala quando... (ILIA, grifo nosso)

Paulo Freire, extensamente em sua obra, discutiu a importância do diálogo. Principalmente por que o diálogo significa encontro, e para ele é uma necessidade existencial (FREI$R E$, 1983), em seu sentido mais amplo. Para Freire, o diálogo é uma possibilidade amorosa, no sentido do compromisso, do respeito com a relação estabelecida com o outro. Por isso, falar de relação com o aprender e com o conhecimento escolar, com os professores e com a escola, pressupõe falar de diálogo.

A relação dos jovens com a escola muda quando os professores se colocam em uma postura mais aberta. E mesmo que essa postura assuste, e como os colegas de Aline apontam, "a professora não passa matéria ou não manda copiar nada", parece que são esses momentos que marcam. Mais do apenas copiar do quadro ou do livro (mesmo que não haja um problema explícito na natureza dessas práti- 
cas), ter momentos em que professor e estudantes dialogam parece fundamental.

O diálogo implica a escuta, e esta "[...] significa a disponibilidade permanente por parte do sujeito que escuta para a abertura à fala do outro, o gesto do outro, às diferenças do outro" (FREIRE, 2016, p. 117). Freire e Shor (2006) destacam que o diálogo, mais do que uma tática para alcançar um objetivo, mesmo que esse objetivo seja a aprendizagem de todos, é também uma possibilidade da condição humana, uma postura necessária para a transformação das pessoas, para a convivência em sociedade. A educação, quando se dá de modo antidialógico, acaba vedando o aspecto comunicativo do ser humano, principalmente porque o diálogo "sela" o relacionamento entre professor e estudante, seres que criticam o mundo através dos conhecimentos escolares.

Outra ideia importante para os autores é que o professor transforma o seu conhecimento quando dialoga, ou seja, sua "cognoscibilidade" é transformada ao ser compartilhada com os estudantes. Da mesma forma, o pensamento dos estudantes também é reelaborado, quando compartilhado com os professores. Nesse sentido, estabelecer formas dialógicas de educação implica compreender que o diálogo vincula dois sujeitos cognitivos, “[...] é a confirmação conjunta do professor e dos alunos no ato comum de conhecer e reconhecer o objeto de estudo" (FREIRE; SHOR, 2006, p. 124).

Ressaltamos a importância do diálogo, pois é neste sentido que caminha a pesquisa com jovens. Outro aspecto que nos faz caminhar nessa direção é a quantidade de dados e informações obtidos com as entrevistas realizadas com os jovens. Eles, de algum modo, anseiam falar, anseiam dizer aquilo que pensam e que sentem, e quando os professores promovem estes espaços, assim como destacam Leão, Dayrell e Reis (2011), estão permi- tindo uma ligação mais forte entre os jovens e a escola.

Ilia continua narrando, ao apontar que mesmo quando os professores têm consigo a ciência de que dialogar é preciso, pois existem limites institucionais, como os horários dos períodos e a distribuição dos mesmos. Mesmo sabendo da importância de dialogar, os professores têm dificuldade de manter uma relação próxima com os estudantes, principalmente por falta de tempo hábil. De alguma forma, a estudante Ilia que está cursando a formação inicial docente sabe que este é um desafio evidente, e que é um tema sempre presente, quando vamos a eventos, ou participamos em formações de professores.

Pereira (2013) nos lembra que, entre um conjunto de limitações objetivas e a sensação de impotência que, muitas vezes, os professores carregam, a única forma de lidar com a situação é fazendo circular a palavra, circular os medos, os anseios, as dificuldades e também as aprendizagens. Desse modo, professores que dialogam parecem deixar marcas positivas na relação dos jovens com a escola, principalmente, quando estes são o motivo dos estudantes investirem na educação e também se tornarem professores.

\section{"Ela fazia a gente entender os conteúdos": o professor que "faz entender"}

Durante as narrativas dos jovens estudantes, percebemos que, além do professor que dialoga, que conversa com os estudantes, há a representação de outro professor: o professor que de algum modo torna a aula interessante e que faz entender o conteúdo. Vide as narrativas dos jovens estudantes:

E aí eu acho... agora pensando nas aulas de biologia, principalmente, era uma necessidade a gente aprender aquilo, e ela tornava o corpo 
humano interessante, tornava os fungos interessantes, tornava... A gente fez tanta coisa, a gente fez um biodigestor, era cocô de cavalo e de porco, aquilo era a coisa mais interessante do mundo. Tudo! Então, eu acho que ela percebia o que era necessidade, tanto de conteúdo programático quanto, como, considerando a gente, no nosso nivel ali, entendeu? (ALINE, grifo nosso)

[A Professora de Português] ela foi uma ótima professora, ela fazia a gente entender os conteúdos e também era minha amiga, também tinha outras atividades de oficina assim, além dos cadernos e do quadro. Essa que se destacou, agora lembrando dela. Mas era mais o professor aqui e o aluno aqui [indicando a distância com as mãos]. (CHRISTINE, grifo nosso)

O que esses professores têm em comum? Vejamos: para Aline, a professora conseguia, de algum modo, fazer com que se interessasse por ciências. A postura dialógica também está presente, pois a professora se importa com o que eles sabem, com o que pensam, considera as suas aprendizagens e acredita que podem aprender, deposita certa confiança na atuação dos estudantes. Já Christine traz à tona a discussão já realizada, a da relação entre professor e estudante, a amizade.

Um dos aspectos importantes que podemos apreender das narrativas é o de que o professor se importa com os estudantes e acredita que eles podem aprender. Que se mobiliza e continua se preocupando com os estudantes e o que eles sabem. Para Weisz (2000, p. 107), o ato de acreditar é importante, pois:

Se não acreditarmos que os alunos podem aprender, se não estivermos convencidos de que podemos de fato ensiná-los, não teremos o empenho necessário para identificar o que sabem ou não e, a partir daí, planejar as intervenções que podem ajudá-los a avançar em suas aprendizagens... os alunos sentem quando não acreditamos que podem superar suas dificuldades, mesmo que digamos o contrário - este é um território em que não é o discurso que man$\mathrm{da}$, mas a crença que nos orienta.
0 acolhimento e o respeito do professor em relação ao estudante pode ser um fator importante. Schwartz (2014) nos lembra que muitos estudantes já começam o ano "fadados ao fracasso". Não que essa condição seja natural, mas porque, por alguma razão, determinado professor não se empenha em dar importância suficiente à relação pedagógica com determinados estudantes e estes, aos poucos, deixam de se engajar na atividade escolar e acabam cumprindo as expectativas dos professores. Os motivos podem ser muitos, como a "indisciplina" ou a "determinação/probabilidade" familiar que diz a muitos professores que determinados jovens não aprendem porque a família não tem formação cultural suficiente ou condições econômicas, discurso corrompido da sociologia da educação (CHARLOT, 2000, 2013).

Desse modo, podemos inferir que, quando o professor se preocupa com o estudante, o quer bem, se mobiliza no sentido de fazer o estudante compreender o conteúdo, constrói estratégias e intervenções, de modo que este se aproprie dos conhecimentos, aumentando assim as chances de que esse estudante também se mobilize. Aí também surge os recursos utilizados, como apontam Aline e Christine, através de jogos, blocos, oficinas etc. 0 professor que faz entender, circula por um conjunto variado de ideias e concepções, que ultrapassam uma forma certa de atuar, ou um "manual do bom professor".

Quando os professores se mostram próximos dos estudantes, e, de algum modo os fazem se interessar pela matéria, perguntam o que aprenderam e o que não aprenderam, buscam saber mais sobre os estudantes, mostram seu interesse pedagógico, que não é só direcionado ao estudante, mas também a si mesmos, ao amor que têm por aprender e ensinar. 0 interesse pedagógico também desenvolve o potencial de observação do professor: impede que faça juízos superficiais sobre o estudante, 
porque o conhece e considera as aprendizagens que os estudantes desenvolvem.

Para Van Manen (2010, p. 39, tradução nossa), a experiência do contato e do compromisso traduz-se na "experiência de ser visto": "Sentir-se visto é mais que sentir-se reconhecido. Para a criança, significa experimentar que é visto pelo professor. Significa que se confirma sua existência, que é uma pessoa única e um aluno único". 5

O conjunto de ideias discutidas nas últimas ações abre um leque de possibilidades que lançam luz sobre a docência, o professor e a relação do estudante com a escola, com seu aprender e com os conhecimentos escolares. Há alguns professores que deixam sua marca nos estudantes, seja pelo cuidado, seja por seu conhecimento, que chama a atenção dos estudantes, e a relação que estabelece com eles faz com que eles se interessem por determinado conteúdo/área etc. As narrativas dos jovens estudantes da pesquisa, mesmo que o referencial de Charlot (2013) dê ênfase à atividade do estudante, destaca o quão importante é a ação do professor e como sua manifestação influencia o olhar e a ação do estudante.

\section{"Eu sei e vocês não sabem": impactos negativos da prática docente na relação com os estudantes}

As narrativas dos estudantes, embora ressaltem a importância da amizade e da postura dialógica como elementos que fortalecem a relação do jovem com a escola, também apresentam impactos negativos, através de acontecimentos e posturas. Ainda mais quando diz respeito à confiança, ao autoritarismo, quando o estudante acredita que o professor não sabe

5 No original: "Sentirse visto es más que sentirse reconocido. Para el niño significa experimentar que es visto por el profesor. Significa que se confirma su existencia, que es una persona única y un alumno único". ensinar, até quando o professor mantém uma postura distante e reservada. As narrativas de Leonardo podem nos ajudar a entender esses aspectos:

É complicada essa questão do educador que eu sempre costumo questionar, é que "ok, tu tem que saber o que tá dando", mas tu tens que saber transmitir aquilo também. No momento que tu tem o conhecimento e não sabe transmitir, tu não tá sendo professor. Tu tá apenas passando informação, e não conhecimento. (LEONARDO)

Já esse professor de matemática o quesito dele era "eu sei e vocês não sabem", então é aquele momento que o professor se sente superior, $e$ acho que quando chega nesse ponto a pessoa não é um bom instrutor, não vai ser. (LEONARDO)

Leonardo demonstra uma grande recusa ao professor, quando este se mostra superior, autoritário, podemos dizer, o que produz uma distância muito grande entre o estudante e si mesmo. Para Freire (2016), uma das maiores tensões educativas é o conflito entre liberdade e autoridade, principalmente quando, por um lado, se instaura o autoritarismo (autoridade exacerbada que se perde, principalmente em seus princípios) ou, de outro modo, a licenciosidade (liberdade exacerbada que beira a falta de compromisso), sem encontrar o equilíbrio capaz de construir uma relação com base na autoridade necessária, para construir uma relação educativa.

Acreditamos que encontrar um equilíbrio de posições é complicado, principalmente, quando lemos uma narrativa como a de Leonardo. Se o papel do professor é promover a construção de conhecimentos, sua autoridade deve servir para que isso se torne possivel, mas não que isso se torne elemento de antidemocracia. À liberdade também cabe limites, quando esta impede a aprendizagem, no sentido de que exime o professor de sua autoridade, torna a sala de aula um lugar no qual se faz tudo menos estudar. 
Para pensar sobre o autoritarismo, fazemos o caminho contrário, pensando em termos de autoridade. Aquino (1999) escreve que a autoridade aparece como reguladora das relações entre sujeitos, principalmente quando estes se encontram sob uma égide institucional. A autoridade envolve a ocupação de um lugar social dentro da relação, principalmente quando é relacionada ao reconhecimento e ao consentimento do outro. A autoridade é legitimada, mas, para que possa ser legitimada, é constantemente atualizada, construída, exigido um trabalho contínuo de manutenção. Por isso, o vínculo de autoridade com os estudantes é algo provisório, precisando de um trabalho contínuo.

Junto ao autoritarismo, travestido de segurança, confiança e distância entre professor e estudante, Leonardo, também em sua narrativa, destaca a importância do ensinar, saber o conteúdo e saber "transmitir". Nesse sentido, parece que a autoridade está fortemente relacionada ao conhecimento, uma autoridade que não se legitima no medo e na ameaça (autoritarismo), mas sim pelo conhecimento que o professor tem, ou como escreve Aquino (1999, p. 138) pela relação de dependência: “A relação é disparada pela crença comum de que um possui, ou guarda, algo de que os outros carecem, o que confere ao primeiro algumas características particulares". Podemos perceber isso na narrativa de Jean, que, mesmo com o conhecimento que o professor possui, ele também tem papel de orientação e esclarecimento, sobre os caminhos que podem ser tomados pelos estudantes:

[...] eu vi que os professores realmente sabiam, incentivavam a tu estudar e mostrava as oportunidades [...] depois que eu aprovei eu vi a oportunidade que era pra estudar, os professores sempre incentivando, incentivando, incentivando, tanto é que foi lá em São Vicente que eu aprendi a falar inglês, foi lá em São Vicente que eu aprendi a fazer, resolver as equações de fisica, fazer os cálculos da matemática, fazer as fórmulas de química, foi lá em São Vicente. (JEAN, grifo nosso)

Nesse sentido, a autoridade do professor vincula-se a um papel de sabedor. Segundo Davis e Luna (1991, p. 69 apud AQUINO, 1999, p. 139-140):

Um professor, para ser reconhecido como autoridade que merece confiança, precisa, ainda, de maestria no exercício de sua função. Isto significa que a autoridade do professor constitui-se a partir da aliança entre conhecimento e experiência na condução de classe: para encaminhar os alunos para a apropriação de determinado fenômeno do real, é preciso que o professor domine tanto o fenômeno a ser conhecimento como o processo de conhecer.

Masschelein e Simons (2017) destacam essa relação de outra forma: o professor amateur, ${ }^{6}$ que talvez poderíamos traduzir na pessoa daquele professor que ama o que conhece, não o que trabalha por vocação (discurso que desvaloriza a docência enquanto profissão), mas sim por amor ao conhecimento que possui e que se preocupa em "transmitir esse desejo" aos estudantes. Assim, o professor tem um compromisso com o mundo e com as novas gerações: sua autoridade se alicerça no conhecimento que possui e que sabe que é importante para os seus estudantes. A autoridade depende "[...] do trabalho engenhoso, árduo e compromissado daquele que, de fato, se dispõe a ensinar algo a outrem" (AQUINO, 1999, p. 40).

Ilia demonstra, em sua narrativa, outro fato que nos interessa, do ponto de vista da relação com o conhecimento e com o professor:

Teve um professor que era mais de idade e já tinha... ele era conhecido por ser muito durão, então ele dava inglês, só que, ele trouxe uma maneira... as aulas dele davam certo... não medo, mas a gente ficava meio receoso nas aulas, por-

6 "Em suma, o professor amateur ama sua matéria e acredita que deve ser dada à todos, repetidas vezes, a oportunidade de se engajarem na matéria que ele ama". (MASSCHELEIN; SIMONS, 2017, p. 84) 
que era outra língua que nós estávamos aprendendo, e uma outra maneira dele trabalhar com a gente, e era língua inglesa. [...] Então, nós tínhamos esse receio, mas ele trabalhava com uma maneira diferente da gente sentar, criava relações pra gente formar alguns diálogos pra interagir entre os estudantes, mas então... [...] a gente tinha muito medo de sermos marcados... aquele professor que percebe que tu tem dificuldade e muitas vezes acaba te marcando de certa forma, ou criando certo atrito entre a relação. Então, muitas vezes a gente fazia as atividades ou tentava fazer algo pra por mais questão de medo [...]. (ILIA)

Sobre a relação da jovem Ilia com o professor, podemos perceber, então, que depende de outros aspectos. A relação baseia-se em conhecimento, mas também, na interação, que é o que se pode compreender na narrativa de Ilia, principalmente quando esta se dá de modo receoso, inconfiável. As narrativas em seções anteriores destacavam que a amizade com o professor era um elemento fundamental, mas aqui aparece o contrário: a impossibilidade de uma relação próxima, mesmo com determinada "competência pedagógica". Não se espera apenas amizade dos professores, entretanto, os jovens da pesquisa destacam isso como um ponto positivo. Ilia, com esse professor de inglês, destaca que o medo, principalmente de algum tipo de discriminação, "de ser marcada", são elementos que imprimem uma marca na trajetória da estudante.

As narrativas de Jean e Aline destacam um dos lados pouco explorados até o momento: quando a licenciosidade se alia à uma possível falta de cuidado ou atenção com o estudante:

Ah, eu fazia reforço, fiz reforço de fisica, fiz reforço de química, fiz reforço de matemática. $E$ quando a escola não disponibilizava reforço eu tinha que fazer aula particular, porque eu tinha muita dificuldade nessas disciplinas e como eu era uma aluna considerada boa, geralmente não me davam reforço de primeira, tipo, eu ia mal numa prova daí eu dizia "prof. eu não entendi nada, me deixa ir no reforço", daí "ah não, tens alunos que são piores que tu, aí tu vai no reforço... deixa, tem pessoas que tem prioridade". Aí eu ia muito mal, quase reprovava, daí me colocavam no reforço. (ALINE)

Em química por falha minha e do professor, porque o professor chegava, dava 5 minutos de aula e saía. Não aprendia nada. (JEAN)

Outro caso é quando a licenciosidade compromete a ação do estudante, que, de algum modo, ou se "aproveita", lança mão de uma tática ou até estabelece uma estratégia, ${ }^{7}$ na acepção de Certeau (2004), e cria uma relação frágil com o conhecimento, ou quando acaba denunciando essa licenciosidade por parte do professor:

Na escola tu só ia na aula, tu não precisas fazer nada. Eu via gente só jogando carta, outros, o pessoal ia bêbado, ia chapado pra aula, tinha um piá que saía assim no meio da aula com uma guria e ia lá pra o banheiro, "pegar ela", então, tipo, tava todo mundo "cagando", e passava. Eu fiz um teste, já que como era trimestre, nessa antiga escola onde fiz o primeiro ano, eu fiz assim: eu passei nos dois primeiros trimestres, então já tava aprovado né, então no terceiro eu "ah, então não vou fazer nada né" e fiz de propósito de ficar com a nota baixa, tava 38 e a média era 50. De lá a professora só olhou, botou a mão na minha mão e disse: "vou te dar a média", daí falei: "não, não precisa, to aprovado", [ela diz:] "vou te dar a média", daí eu: "não precisa, to aprovado, vou sair dessa escola", porque eu já tava fazendo processo seletivo para o Instituto Federal, daí ela me deixou com média, eu querendo ficar sem média eu fiquei com média, daí eu vi que era só tu ir na aula. Daí eu fui pra o IF com esse mesmo pensamento, "é só eu ir na aula", daí eu comecei a faltar lá, daí eu vi que não era assim quando eu reprovei [...]. (JEAN)

7 Tática e estratégia são movimentos diferentes para Certeau (2004). Enquanto a tática se faz de pequenos movimentos, que são realizados aos poucos, nem sempre tem sua possibilidade garantida, porque são pequenos golpes de ocasião, a estratégia é mais consolidada, tem condições estáveis de acontecimento, implica repetição. 
Podemos perceber que, quando não existem procedimentos claros, atividades com fins definidos, uma autonomia discente moderada e uma autoridade docente competente, parece que a aula se esvazia de sentido. Por que ir para uma aula no qual qualquer um faz o que quer? Para que estudar para fazer um trabalho se o estudante entrega o trabalho "de qualquer jeito" e não existe nenhuma cobrança ou explicação daquilo? São estes pequenos momentos que vão dando um contorno "despreocupado" com a realidade escolar. Aí, talvez seja por isso que muitos estudantes ao final já não se preocupam tanto e acabam constituindo ações utilitaristas (PERRENOUD, 1995): a ausência de uma organização coerente pode estar produzindo isso.

Acreditamos que, quando existe um equilíbrio entre autoridade e liberdade, é possível que se expresse a amorosidade posta por Freire: "A amorosidade freireana que percorre toda sua obra e sua vida se materializa no afeto como compromisso com o outro que se faz engravidado da solidariedade e da humildade" (FERNANDES, 2008, p. 37). Um afeto que não se esquece do ato de conhecer, de aprender, de descobrir aspectos do mundo, de cobrar atitude do estudante sempre que necessário; uma autoridade que não rompe a liberdade e que não impõe silêncios desnecessários; uma prática docente que não se esquece do seu compromisso com os estudantes, e que esse possa repercutir na memória e nas atitudes dos mesmos, principalmente, quando estes também se tornarem professores.

\section{Considerações finais}

O objetivo deste artigo foi discutir as relações que os jovens estudantes estabelecem com seus professores e suas práticas no Ensino Médio, e o impacto dessas em sua interação com a escola. Através das narrativas de seis jovens estudantes de licenciatura de uma universidade da região sul foi possivel perceber diferentes relações estabelecidas entre os professores e as suas práticas. As relações estabelecidas e analisadas neste artigo (recortadas de um contexto mais amplo de relações) demonstram como é complexa a relação do jovem com a escola. Neste sentido, a amizade enquanto forma de relação, a dialogicidade e a aproximação do professor com os estudantes, como forma de mediação, e o entendimento do estudante, atrelado à postura do professor, são relações positivas estabelecidas pelos estudantes. Entretanto, o autoritarismo, o medo, a falta de autoridade docente e/ou as táticas de subversão empregadas pelos estudantes são elementos que marcam negativamente as trajetórias, as aprendizagens.

Os jovens, lembrando Abrantes (2003), vivem a escola de diferentes maneiras. Eles estão lá pela aula, mas também pelaa sociabilidade (CHARLOT, 2013). Assim, como chama a atenção Abrantes (2003, p. 97): “No fundo, é através das redes de sociabilidade que os diversos actores constroem a realidade escolar, atribuindo-lhe significados; é através das relações sociais que os jovens vivem a escola". Pesquisar como os estudantes aprendem, como aprendem e com quem aprendem são desdobramentos necessários para a pesquisa em educação. As relações com os professores podem, nesta direção apontada por Abrantes (2003), se consolidar como uma estratégia importante.

Por fim, vale destacar a abordagem de pesquisa adotada. A pesquisa biográfico-narrativa permite a compreensão dos nossos universos sociais a partir da experiência individual, que também é uma experiência dialogada, dividida com outras pessoas. Entender a escola pela ótica da relação dos estudantes com os professores permite multiplicar os olhares de análise sobre o êxito/fracasso escolar, fundo principal desta pesquisa. Vale destacar, como 
apontado em Martinez, (2017) e Cavaco (2018), a ausência de mais pesquisas que valorizem o olhar e a voz do jovem, apesar da abertura da pesquisa em educação, considerada por Ghedin e Franco (2011). Há que se ampliar o olhar sobre a escola, considerando os estudantes.

Quais as aprendizagens dos estudantes? Como se relacionam com os professores e colegas aqueles que têm bom desempenho na escola? E como se relacionam com os conhecimentos escolares aqueles que "não vão bem"? Essas são algumas perguntas que dão continuidade a esse movimento de pesquisa realizado por nós.

\section{Referências}

ABRANTES, Pedro. Os sentidos da escola: identidades juvenis e dinâmicas de escolaridade. Oeiras: Celta Editora, 2003.

AQUINO, Julio Groppa. Autoridade docente, autonomia discente: uma equação possivel e necessária. In: AQUINO, Julio Groppa. (Org.). Autoridade e autonomia na escola: alternativas teóricas e práticas. São Paulo: Summus, 1999. p. 131-153.

BOLÍVAR, Antonio; DOMINGO, Jesús; FERNÁNDEZ, Manuel. La investigación biográfico-narrativa en educación: enfoque y metodologia. Madrid: Editorial La Muralla S.A., 2001.

CAVACO, Carmen. A investigação biográfica em educação no contexto português. Revista Brasileira de Pesquisa (Auto)Biográfica, Salvador, v. 03, n. 09, p. 814-828, set./dez. 2018. Disponivel em: <https:// www.revistas.uneb.br/index.php/rbpab/article/ view/5595/3535>. Acesso em: 22 jan. 2019.

CERTEAU, Michel de. A invenção do cotidiano: artes de fazer. Tradução de Ephraim Ferreira Alves. 10. ed. Petrópolis, RJ: Vozes, 2004.

CHARLOT, Bernard. Da relação com o saber: elementos para uma teoria. Porto Alegre: Artmed, 2000.

Da relação ao saber às práticas educativas. 1. ed. São Paulo: Cortez, 2013. (Coleção Docência em Formação: saberes pedagógicos).
CLANDININ, D. Jean; CONNELLY, F. Michael. Pesquisa narrativa: experiências e história na pesquisa qualitativa. Tradução do Grupo de Pesquisa Narrativa e Educação de Professores ILEEL/UFU. 2. ed. Uberlândia, MG: EDUFU, 2015.

FERNANDES, Cleoni. Amorosidade. In: STRECK, Danilo R.; REDIN, Euclides; ZITKOSKI, Jaime. (Orgs.). Dicionário Paulo Freire. Belo Horizonte: Autêntica Editora, 2008. p. 37-39.

FERRETI, Celso João; SILVA, Monica Ribeiro da. Reforma do ensino médio no contexto da medida provisória no 746/2016: estado, currículo e disputas por hegemonia. Educ. Soc., Campinas, v. 38, n. 139, p. 385-404, abr./jun. 2017.

FOLLMANN, José Ivo; FISCHER, Nilton Bueno. Apresentação da edição brasileira. In: MELUCCl, Alberto. $\mathbf{0}$ jogo do eu: a mudança de si em uma sociedade global. São Leopoldo, RS: Editora da Unisinos, 2004. p. 9-11.

FREIRE, Paulo. Pedagogia do oprimido. 16. ed. Rio de Janeiro: Paz e Terra, 1983.

Pedagogia da autonomia: saberes necessários à prática educativa. 53. ed. Rio de Janeiro: Paz e Terra, 2016.

; SHOR, Ira. Medo e ousadia: o cotidiano do professor. 11. ed. Rio de Janeiro: Paz e Terra, 2006.

GHEDIN, Evandro; FRANCO, Maria Amélia Santoro. Questões de método na construção da pesquisa em educação. 2. ed. São Paulo: Cortez, 2011.

GONÇALVES, Suzane da Rocha Vieira. Interesses mercadológicos e o "novo" ensino médio. Revista Retratos da Escola, Brasília, v. 11, n. 20, p. 131-145, jan./jun. 2017.

LAHIRE, Bernard. Homem plural: os determinantes da ação. Tradução de Jaime A. Clasen. Petrópolis, RJ: Vozes, 2002.

LARROSA, Jorge. Notas sobre a experiência e o saber de experiência. Revista Brasileira de Educação, Rio de Janeiro, n. 19, p. 20-28, jan./abr. 2002. Disponivel em: <http://www.scielo.br/pdf/rbedu/n19/n19a02. pdf>. Acesso em: 20 out. 2016. 
LEÃO, Geraldo; DAYRELL, Juarez Tarcísio; REIS, Juliana Batista dos. Jovens olhares sobre a escola do ensino médio. Cad. CEDES, Campinas, v. 31, n. 84, p. 253-273, ago. 2011. Disponivel em: <http:// www.scielo.br/scielo.php?script=sci_arttext\&pi$d=S 0101-32622011000200006 \&$ lng $=e n \& n r m=i s 0>$. Acesso em: 05 jun. 2017.

MASSCHELEIN, Jan; SIMONS, Maarten. Em defesa da escola: uma questão pública. Tradução de Cristina Antunes. 2. ed. 2. reimp. Belo Horizonte: Autêntica Editora, 2017.

MARTINEZ, Lucas da Silva. Escutar os jovens como princípio na pesquisa em educação. In: ALMEIDA, Márcia Tereza Fonseca; SOARES, Ilma Maria Fernandes; SILVA, Renato Martins e. (Orgs.). Temas em Debate. Rio de Janeiro: Dctio Brasil, 2017. p. 43-67. v. 1.

“Eu não gostava nem odiava porque eu não entendia nada!": relações com a escola, o aprender e os conhecimentos escolares no Ensino Médio. 2018. 272 f. Dissertação (Mestrado em Educação) Programa de Pós-Graduação em Educação, Universidade Federal de Santa Maria, Santa Maria, 2018.

MARTINEZ, Lucas da Silva; SALVA, Sueli. Entre explicações, diálogos, interesses... questionando a metodologia no Ensino Médio a partir de narrativas. In: ENCONTRO HUMANÍSTICO MULTIDISCIPLINAR, CONGRESSO LATINO-AMERICANO DE ESTUDOS HUMANÍSTICOS MULTIDISCIPLINARES, 3., 2., 2017, Jaguarão/RS. Anais... Jaguarão/RS: CLAEC, 2017. p. 1-5. Disponivel em: <http://eventos.claec.org/index.php/ ehm/3ehm/paper/view/754/311>. Acesso em: 29 mar. 2019.

Discutindo a proposta do "Novo Ensino Médio" com base em narrativas juvenis. In: GUSTSACK, Felipe; VIANNA, Rafael de Brito; ROTHMUND, Angela Alenice (Orgs.). Educação básica e pesquisa: volume 1. 1. ed. Santa Cruz do Sul, RS: EDUNISC, 2018. p. 1526. Disponivel em: <https://www.unisc.br/images/ upload/com_editora_livro/e-book_EDUCACAO-BASICA-E-PESQUISA-v-1-.pdf>. Acesso em: 29 mar. 2019.

MELUCCl, Alberto. A invenção do presente: movimentos sociais nas sociedades complexas. Petrópolis, RJ: Vozes, 2001.
O jogo do eu: a mudança de si em uma sociedade global. São Leopoldo, RS: Editora da Unisinos, 2004.

Busca de qualidade, ação social e cultura: por uma sociologia reflexiva. In: MELUCCI, Alberto. (Org.). Por uma sociologia reflexiva: pesquisa qualitativa e cultura. Tradução de Maria do Carmo Alves do Bonfim. Petrópolis, RJ: Vozes, 2005. p. 25-42.

MORAES, Roque. Uma tempestade de luz: a compreensão possibilitada pela análise textual discursiva. Ciênc. educ., Bauru, v. 9, n. 2, p. 191-211, jul./dez. 2003. Disponível em: <http:// www.scielo.br/scielo.php?script=sci_arttext\&pi$\mathrm{d}=\mathrm{S} 1516-73132003000200004 \&$ lng $=$ en \& $\mathrm{nrm}=\mathrm{iso}$ >. Acesso em: 28 jun. 2017.

PEREIRA, Marcelo Ricardo. Os profissionais do impossivel. Educação \& Realidade, Porto Alegre, v. 38, n. 2, p. 485-499, abr./jun. 2013.

PERRENOUD, Philippe. Ofício de aluno e sentido do trabalho escolar. Porto: Porto Editora, 1995. (Colecção Ciências da Educação).

QUEIROZ, Andrea Mathias. Experiências formativas em música na construção dos projetos de vida dos jovens: um estudo a partir de entrevistas narrativas. Revista Brasileira de Pesquisa (Auto)Biográfica, Salvador, v. 02, n. 05, p. 470-482, mai./ago. 2017. Disponivel em: <https://www.revistas.uneb.br/index.php/rbpab/article/view/3667>. Acesso em: 20 set. 2018.

SALVA, Sueli. Narrativas da vivência juvenil feminina: histórias e poéticas produzidas por jovens de periferia urbana de Porto Alegre. 2008. 392 f. Tese (Doutorado em Educação) - Programa de Pós-Graduação em Educação, Universidade Federal do Rio Grande do Sul, Porto Alegre, 2008.

SCHWARTZ, Suzana. Motivação para ensinar e aprender: teoria e prática. Petrópolis, RJ: Vozes, 2014.

SILVA, Monica Ribeiro da.; SCHEIBE, Leda. Reforma do ensino médio: pragmatismo e lógica mercantil. Retratos da Escola, Brasília, v. 11, n. 20, p. 19-31, jan./ jun. 2017.

SOUZA, Elizeu Clementino de.; SOARES, Liane Figuei- 
redo. Histórias de vida e abordagem (auto)biográfica: pesquisa, ensino e formação. In: BIANCHETTI, Lucídio; MEKSENAS, Paulo. (Orgs.). A trama do conhecimento: teoria, método e escrita em ciência e pesquisa. Campinas, SP: Papirus, 2008. p. 191-203.

TARDIF, Maurice. Saberes docentes e formação pro-

fissional. 11. ed. Petrópolis, RJ: Vozes, 2010.
VAN MANEN, Max. El tono de la enseñanza: el lenguaje de la pedagogía. 4. reimp. Barcelona: Paidós, 2010.

WEISZ, Telma. 0 diálogo entre o ensino e a aprendizagem. São Paulo: Ática, 2000.

Recebido em: 16/11/2018

Aprovado em: 26/03/2019

Lucas da Silva Martinez é Pedagogo pela Universidade Federal do Pampa. Mestre e Doutorando em Educação pela Universidade Federal de Santa Maria. e-mail: lukasspedagogia@gmail.com

Rua Vale Machado, no 1635, apto. 302, Centro, Santa Maria, RS, CEP 97010-530. Telefone: (55) 98433-9040.

Sueli Salva é Doutora em Educação pela Universidade Federal do Rio Grande do Sul. Professora Associada da Universidade Federal de Santa Maria. e-mail: susalvaa@gmail.com

Rua Pedro Américo, 247, apto. 702, Camobi, Santa Maria, RS, CEP 97110-580. Telefone: (55) 99994-2499. 